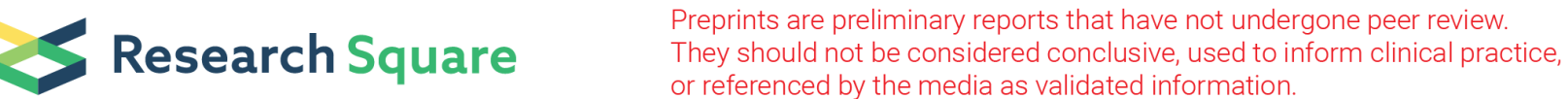

\section{Occupational-Related Shoulder and Neck Pain Among the Working Population of Ethiopia: Systematic Review and Meta-Analysis}

Dechasa Adare Mengistu ( $\nabla$ dechasaadare@gmail.com )

College of Health and Medical Science, Haramaya University https://orcid.org/0000-0002-0076-5586

\section{Yohannes Mulugeta Dammu}

College of Health and Medical Science, Haramaya University

\section{Desi Debelu}

haramaya University

Liku Muche

Haramaya University

\section{Salie Mulat}

Haramaya University

Ashenafi Berhanu

Haramaya University

Mohammed Muzeyin

Haramaya University

\section{Fila Ahmed}

Haramaya University

\section{Systematic Review}

Keywords: ergonomic hazard, musculoskeletal disorders, neck pain, occupational health hazards, shoulder pain, Ethiopia

Posted Date: December 6th, 2022

DOI: https://doi.org/10.21203/rs.3.rs-140997/v5

License: (c) (i) This work is licensed under a Creative Commons Attribution 4.0 International License.

Read Full License 


\section{Abstract}

Background. Currently, work-related musculoskeletal disorders are a significant public health concern and are one of the leading causes of disability-adjusted life years and reduced quality of life. Therefore, the current study aimed to determine the country-wide prevalence of work-related musculoskeletal disorders, particularly shoulder and neck pain, in Ethiopia.

Methods. This study considered studies conducted in Ethiopia, written in English and published in 20172020 and searched using electronic databases such as PubMed/MEDLINE, Web of Science, Google Scholar, CINAHL, SCOPUS, Embase, African Index Medicus, and African Journals Online database. The quality assessment of the studies was done using Joanna Briggs Institute Critical Assessment tools to determine the relevance of each included article to the study.

Results. The study found that the pooled prevalence of shoulder and neck pain in the previous year represented $37.9 \%$ [95\% Cl:26.5, 50.8\%] and $29.9 \%$ [95\% Cl: 20.1, 41.9], respectively. Based on the subgroup analysis, the pooled prevalence of shoulder pain in the last year based on the study population, publication year and study region was $47.6 \%$ [95\% Cl: 45.8, 49.4\%], 49.8\% [95\% Cl: 45.7, 53.9\%] and 44.6\% [95\% Cl: $41.4,47.8 \%]$, respectively, while the pooled prevalence of neck pain in the last year based on the study population, publication year and study area was 39.1\% (95\% Cl: $37.5,40.7 \%$ ], $25.1 \%$ [ 95\% Cl: 20.8, $29.9 \%]$ and $32.6 \%$ [95\% Cl: 29.8, 35.5\%], respectively.

Conclusions This study found that at least one third of the study participants had experienced occupational-related shoulder and/or neck pain in the previous year. The study suggests that there is a need to implement occupational health and safety measure to reduce work-related musculoskeletal disorders and other hazards.

\section{Introduction}

Musculoskeletal disorders (MSD) are a major public health problem that affects various regions of the body, such as the shoulder, elbow, lower back, hips, knees, wrist, neck, hands, upper back, ankle, and feet [1-3] and are characterized by symptoms such as pain, ache, and discomfort [4,5]. Workers working in different working environments such as health care, driving, the manufacturing industry, general labor, maintenance, repair, and cleaning are potentially at risk of musculoskeletal disorders [6].

According to the Global Burden of Disease report in 2016, MSDs were among the leading causes of disability-adjusted life years [7] with a double burden of economic costs, healthcare service utilization, and social problems $[8,9]$. Occupational-related health problems such as shoulder and neck pain are among the most common causes of morbidity and absenteeism from work and reduced productivity in many countries [10-13] and have multifactorial biopsychological origins and socioeconomic costs $[9,13$, 14-16]. 
Neck pain affects two-thirds of all people at some point in their lives [17]. From 1990 to 2010, the effect of adjusted life years on neck pain increased from 23.9 million to 33.6 million [18]. According to the Global Burden of Diseases report in 2015, neck pain was among the leading causes of disability in most parts of the country [19].

In developing countries, the implementation of occupational health and safety practices is often neglected and preventive measures are poor [20]. As a result of lack of an adequate training, poor awareness, and under-reporting of problems, MSD related to work has increased in developing countries [21] and remains less prioritized [22]. In Ethiopia, several studies are conducted on work-related MSDs such as neck and shoulder in various occupational settings [23-33].

However, there is no study that provides adequate evidence on the overall pooled prevalence of workrelated MSDs such as neck and shoulder MSDs that can be crucial for policy makers or / and the ministry of health in designing prevention and control programs and for a better understanding of the current evidence on the prevalence of shoulder and neck pain. Therefore, this study aimed to determine the pooled prevalence of shoulder and neck musculoskeletal disorders related to work related to work in Ethiopia.

\section{Methods}

This study aimed to determine the overall prevalence of shoulder and neck musculoskeletal disorders in the previous year. The study was carried out according to the Preferred Reporting Items for Systematic Reviews and Meta-Analysis (PRISMA) guidelines [34].

\section{Eligibility criteria.}

Articles that met the following predetermined inclusion criteria were included in the systematic review and meta-analysis.

i. Population: A working population of Ethiopia regardless of their occupation.

ii. Outcome. Articles on the prevalence of MSD reported a one-year prevalence of shoulder and/or neck pain.

iii. Study design: A cross-sectional study that provides quantitative results (magnitude, frequency, or prevalence or rate).

iv. Study location: Full-text articles conducted in Ethiopia

v. Publication issue: Peer-reviewed journal articles published between 2017 and 2020

vi. Language: Full-text articles written in English.

\section{Data/Information Sources and Search Strategies.}

The searches of the literature were performed using keywords from systematic review and meta-analysis using search strategies such as the databases SCOPUS, PubMed/ MEDLINE, Embase, Cochrane 
Library, African Index Medicus, Google Scholar, CINAHL, and African Journals online. Articles were searched using a combination of Boolean logic operators ("AND, OR and NOT"), medical subject headings (MeSH), and keywords.

The following are among the search terms that the authors (DA. Mengistu and YM. Demmu) used in the initial search of literature from included databases: "Prevalence" OR "Magnitude" AND "Occupational" OR, "Occupational related" OR "Work related" OR "Ergonomic related" AND "Musculoskeletal" OR "shoulder" OR "Neck" AND "Disorders" OR "Disease" OR Problems" OR "Pain" OR "Injury" AND "Working group" OR "Working population" OR "Workers" AND "Ethiopia.

Furthermore, manual searching of the literature was performed to cover those articles that were difficult to locate and missed from the included electronic databases. Finally, all identified keywords and index terms were checked across the electronic databases. The last search was done on August, 222020.

\section{Outcomes Measure}

The primary outcome of interest was the prevalence of occupational-related shoulder and neck disorders/pain that was estimated or reported by dividing the disorders experienced by the total population at a given time. Furthermore, the prevalence of shoulder and neck pain was estimated by dividing the number of people who experienced shoulder or neck pain by the sample size of each study for articles that did not report the prevalence or rate.

\section{Study selection}

Duplicated articles were removed using the ENDNOTE software version X5 (Thomson Reuters, USA). The authors (DA. Mengistu and YM. Demmu) screened the titles and abstracts of the identified articles by applying the inclusion and exclusion criteria.

The study selection process was performed using the PRISMA flow chart showing the articles included in the study and the articles excluded from the study for reasons. Finally, the systematic review and metaanalysis included studies conducted in Ethiopia and published from 2017 to 2020 that reported the prevalence of shoulder and neck musculoskeletal disorders last year.

\section{Data Extraction and Quality Assessment}

The author extracted the required data from the eligible articles. The following data were extracted for the study: author/s; year of publication; sample size, study region; study design; and primary results were extracted using the Microsoft Excel 2016 format.

The selected articles were subjected to a rigorous evaluation using standardized critical evaluation tools, Joanna Briggs Institute (JBI) Critical Evaluation Tools) [35] to determine the quality and relevance of each article by the authors independently. The evaluation tools have the following nine evaluation criteria/ parameters; (1) appropriate sampling frame; (2) proper sampling technique; (3) adequate sample 
size; (4) description of the study subject and setting description; (5) sufficient data analysis; (6) use of valid methods for identified conditions; (7) valid measurement for all participants; (8) use of appropriate statistical analysis and (9) adequate response rate.

Then, the score was taken across the articles and classified as high ( $85 \%$ and above score), moderate (60-85\% score), and low ( $<60 \%$ score) quality. The included articles were subjected to the evaluation (appraisal) of the authors (DA. Mengistu and YM. Demmu) independently to check the accuracy of the work and reduce the error.

\section{Data Analysis and Statistical Procedures.}

The pooled prevalence of MSD related to shoulder and neck pain in the previous year was done using Comprehensive Meta-Analysis (CMA) version 3.0 statistical software. Furthermore, the forest plot, and the random-effects model were used to determine the pooled prevalence of shoulder and neck pain in the previous year.

The publication bias of the included studies was evaluated using funnel plots and the P-value of $<0.05$ was considered evidence of publication bias. Furthermore, the subgroup analysis was performed according to the year of publication, study population/occupation categories, and study region to minimize random variations between the included studies. Finally, the results were presented using texts, tables, and graphs/figures.

\section{Heterogeneity}

Cochran's $Q$ test, $(\mathrm{Q})$ and (I Squared test) $\mathrm{I}^{2}$ statistics were used to evaluate the heterogeneity among the included articles. $I^{2}$ statistics is the proportion of the variation in prevalence estimates due to genuine variation in prevalence $[36,37]$. Additionally, subgroup analysis was performed based on the years of publication, occupation, and study areas to determine the heterogeneity in the prevalence of shoulder and neck pain.

\section{Results}

\section{Study selection}

About 921 articles and reports were searched through electronic databases such as Web of Science, SCOPUS, PubMed/MEDLINE, Embase, Google Scholar, CINAHL, African Index Medicus, African Journals Online databases, and Science Direct from July 16 to August 22, 2020. Following the search for articles, 222 duplicate articles were excluded. Furthermore, 443 articles were excluded after initial screening, and 66 articles were excluded after full-text articles were assessed for eligibility. Finally, a total of 11 articles were included in the systematic review and meta-analysis (Figure 1). 
Table 1. Overall characteristics of included articles in the systematic review and metaanalysis, 2020.

\begin{tabular}{|c|c|c|c|c|c|c|c|c|}
\hline \multirow[t]{2}{*}{ ference } & \multirow[t]{2}{*}{$\begin{array}{l}\text { Publication } \\
\text { year }\end{array}$} & \multirow[t]{2}{*}{$\begin{array}{l}\text { Study } \\
\text { period }\end{array}$} & \multirow[t]{2}{*}{$\begin{array}{l}\text { Sample } \\
\text { size }\end{array}$} & \multicolumn{2}{|c|}{$\begin{array}{l}\text { Prevalence of } \\
\text { MSDs }\end{array}$} & \multirow[t]{2}{*}{ Population } & \multirow[t]{2}{*}{ Region } & \multirow{2}{*}{$\begin{array}{l}\text { Risk } \\
\text { of } \\
\text { bias }\end{array}$} \\
\hline & & & & Shoulder & Neck & & & \\
\hline 3] & 2020 & 2019 & 344 & 61.0 & 15.2 & $\begin{array}{l}\text { Vehicle } \\
\text { Repair } \\
\text { Workers }\end{array}$ & SNNP & Low \\
\hline !] & 2020 & 2018 & 307 & 29.6 & 35.2 & $\begin{array}{l}\text { Bank } \\
\text { workers }\end{array}$ & Tigray & Low \\
\hline j] & 2019 & 2017 & 422 & 54.0 & 50.7 & $\begin{array}{l}\text { Hotel house } \\
\text { keepers }\end{array}$ & Amhara & Low \\
\hline j] & 2017 & 2016 & 422 & 68.2 & NA & $\begin{array}{l}\text { Pedestrian } \\
\text { back loading } \\
\text { women }\end{array}$ & SNNP & Low \\
\hline 7] & 2019 & 2018 & 417 & 27.1 & 29.3 & Barbers & Amhara & Low \\
\hline 3] & 2019 & 2017 & 410 & 10.5 & 7.6 & $\begin{array}{l}\text { Construction } \\
\text { workers }\end{array}$ & Oromia & Low \\
\hline 3] & 2020 & 2019 & 419 & 72.1 & 68.3 & Tailors & Amhara & Low \\
\hline )] & 2020 & 2019 & 652 & 53.7 & 53.4 & Hairdressers & Oromia & Low \\
\hline L] & 2020 & 2019 & 264 & 14.0 & 9.5 & Cleaners & Tigray & Low \\
\hline ?] & 2020 & $2016 / 17$ & 755 & 40.9 & 38.0 & $\begin{array}{l}\text { Bank } \\
\text { workers }\end{array}$ & $\begin{array}{l}\text { Addis } \\
\text { Ababa }\end{array}$ & Low \\
\hline 3] & 2018 & 2015 & 301 & 14.1 & 24.0 & Nurses & Oromia & Low \\
\hline
\end{tabular}

Keys: MSDs: Musculoskeletal Disorders; NA: Not Applicable; SNNP: Southern Nations, Nationalities, and Peoples.

\section{Characteristics of the included articles.}

In this study, a total of 4,713 participants were included in 11 articles published in Ethiopia from 2017 to 2020 [23-33]. Regarding the region of the country where the studies were conducted, 3 (27.27\%) articles $[28,30,33]$ were carried out in Oromia, $3(27.27 \%)$ articles $[25,27,29]$ in Amhara, $2(18.2 \%)$ articles $[24,31]$ in Tigray, 2 (18.2\%) in SNNP [23,26] and one (9.1\%) article in the city administration of Addis Ababa [32]. The included studies were cross-sectional studies with a sample size ranging from 264 [31] to 755 [32] study participants. 
Based on the JBI Critical Appraisal tool [35], all included articles had a low risk of bias. The prevalence of shoulder and neck pain related to work in the previous year ranged from $10.5 \%$ [28] to $72.1 \%$ [29] and $7.6 \%$ [28] to $68.3 \%$ [29], respectively.

Among the studies included in this work, $10(90.1 \%)$ [23-25, 27-33] reported the prevalence of shoulder and neck pain, while only one article [26] reported the prevalence of shoulder pain alone. Furthermore, 6 (55.44\%) of the included articles were published in 2020 [23,24, 29-32] while 3(27.27\%) articles $[25,27,28]$ were published in 2019. (Table 1).

\section{Prevalence of Musculoskeletal Disorders}

The meta-analysis was performed using the Comprehensive Meta-Analysis (CMA) Version 3 statistical package (software) to determine the combined prevalence of shoulder and neck musculoskeletal disorders in Ethiopia.

\section{Prevalence of occupational-related shoulder pain}

\section{Overall pooled prevalence of shoulder pain.}

The pooled prevalence of occupational-related shoulder pain in the previous year was found to be $37.9 \%$ with a $95 \% \mathrm{Cl}$ of 26.5 to $50.8 \% ; I^{2}=98.51 \%$ with a P-value $<0.001$ (Figure 2 ).

\section{Subgroup analysis of the pooled prevalence of shoulder pain.}

Based on the subgroup analysis of the pooled prevalence of shoulder pain related to work based on the study population or participants, the overall pooled prevalence of shoulder pain in the previous year was $47.6 \%$ (95\% Cl: $45.8,49.4 \%$ with a $\mathrm{P}$ value of $=0.009$ ]. Furthermore, after performing the subgroup analysis based on the year of publication, the total pooled prevalence of occupational-related shoulder pain in the previous year was $49.8 \%$ with $95 \% \mathrm{Cl} 45.7,53.9 \%$ ) and a $\mathrm{P}$ value of $>0.05$ ]. After the subgroup analysis of the prevalence of shoulder pain was performed by study region, the overall pooled prevalence of occupational-related shoulder pain was $44.6 \%$ with $95 \%$ (supplementary material I).

\section{Prevalence of occupational-related neck pain.}

\section{Overall prevalence of neck pain.}

The pooled prevalence of occupational-related neck pain in the previous year was $29.9 \%$ with a $95 \% \mathrm{Cl}$ of $20.1,41.9 \%$ with a $\mathrm{p}$-value of 0.002 and $\mathrm{I}^{2}=98.29 \%$ with P-value $<0.001$ (Figure 3 ).

\section{Subgroup analysis of the prevalence of occupational-related neck pain.}

After the subgroup analysis of work-related neck pain in the previous year based on the study population, the overall pooled prevalence of occupational-related neck pain in the previous year was $39.1 \%(95 \% \mathrm{Cl}$ $37.5,40.7 \%$ with a P-value of $<0.001)$. After the subgroup analysis was performed based on the year of 
publication, the overall pooled prevalence of neck pain in the previous year was 25.1 percent, with a $95 \%$ $\mathrm{Cl}$ of $20.8,29.9 \%$ ) and a $\mathrm{P}$ value $<0.001]$. Furthermore, after performing the subgroup analysis based on the study region, the total pooled prevalence of work-related neck pain was 32.6 percent, with a $95 \% \mathrm{Cl}$ of $29.8,35.5 \%$ ) and a p-value $<0.001$ (supplementary material II).

\section{Discussion}

This study was aimed to determine the pooled prevalence of occupational-related shoulder and neck pain in the previous year in Ethiopia based on previously published articles. In the current study, a total of 4713 study participants were included in 11 articles published in Ethiopia [23-33].

Musculoskeletal disorders such as neck and shoulder pain are the leading causes of loss of productivity, absenteeism of employees, and affect quality of life. The current study found the pooled prevalence of occupational-related shoulder pain in the previous one-year account 37.9\% [95\% Cl:26.5, 50.8\%; P-value < 0.001]. However, the pooled prevalence of shoulder pain increased to $47.6 \%, 49.8 \%$, and $44.6 \%$ after the subgroup analysis of prevalence based on the study population, publication year, and study region, respectively.

Furthermore, the study found the highest prevalence of shoulder pain (72.1\%) among tailors [29], followed by the prevalence among pedestrian backloading women (68.2\%) [26], vehicle repair workers (61.0\%) [23], hotel housekeepers (54.0\%) [25] and hairdressers (53.7\%) [30], respectively, while the lowest prevalence of shoulder pain or disorders (10.5\%) [28] was reported among construction workers. There is a variation in the prevalence of occupational-related shoulder pain among the included working populations with various occupations. The difference may be due to the variation in activities or nature of work, the availability of occupational health services, and the implementation of occupational health and safety practices.

However, the current study found a pooled prevalence of neck pain related to work in the previous year of $29.9 \%$ [95\% Cl: 20.1-41.9\%; P value $=0.002$ ]. However, the pooled prevalence of neck pain among various working populations increased to $39.1 \%$ and $32.6 \%$ based on the subgroup analysis by the study population and the study region, respectively. However, it was reduced to $25.1 \%$ based on the subgroup analysis of the prevalence of neck pain by publication year. Furthermore, the study found the highest prevalence of neck pain (68.3\%) among tailors [29], followed by the prevalence among hairdressers (53.4\%) [30] and hotel housekeepers (50.7\%) [25], respectively, while the lowest prevalence of neck pain (7.6\%) [28] was reported among construction workers. Variation may be due to differences in activities, work load, or nature of work, and the implementation of occupational health and safety practices.

In general, the current study found that at least two of the seven study participants experienced occupational-related shoulder pain, while three of the eight study participants experienced occupationalrelated neck pain, regardless of the occupation categories. This indicates that occupational-related MSDs continue to have potential health and economic impacts. Thus, the implementation of occupational 
health and safety practices such as engineering control, administrative control, and the use of personal protective devices in the workplace plays an important role in reducing these problems $[38,39]$.

\section{Limitations}

There was an unequal distribution of occupations among the included articles. On the other hand, the prevalence of MSDs such as shoulder and neck pain in some regions of Ethiopia was not covered due to the lack of studies in those regions. Furthermore, cross-sectional studies were included, and causal relationships between MSDs and risk factors cannot be established.

\section{Conclusions}

Occupational-related musculoskeletal disorders continue to have a potential impact on worker health, productivity, and quality of life worldwide. Similarly, the current study found that at least one-third of the study participants experienced occupationally related shoulder and/or neck pain in the previous year. Thus, this study suggests that there is a need to improve and implement occupational health and safety measures to reduce MSDs and other occupational hazards.

\section{List Of Abbreviations}

CDC: Centers for Disease Control and Prevention; CMA: Comprehensive Meta-Analysis; JBI: Joanna Briggs Institute; MSDs: Musculoskeletal Disorders; PRISMA: Preferred Reporting Items for Systematic Review and Meta-Analysis; SNNP: Southern Nations, Nationalities, and Peoples

\section{Declarations}

Ethics approval and consent to participate.

Not applicable.

\section{Consent for publication}

Not applicable.

\section{Availability of data and materials.}

Almost all data are included in this study. However, additional data will be available from the corresponding author upon reasonable request.

\section{Competing Interests}

The author declares that there is no competing interest in this work.

\section{Funding}


Not applicable.

\section{Authors' Contributions}

DAM conceived the idea and played an important role in data review, extraction and analysis, writing, drafting, and editing the manuscript. DAM and YMD have contributed to data extraction and analysis. Finally, the authors (DAM and YMD) read and approved the final version of the manuscript to be published and agreed on all aspects of this work.

\section{Acknowledgments}

I would like to extend my deepest thanks to Haramaya University, Department of Environmental Health staff, for providing their constructive support.

\section{References}

1. Roquelaure Y, Bodin J, Descatha A, Petit A. Musculoskeletal disorders: how to recognize them as occupational diseas. La Revue du praticien. 2018 Dec 1;68(10):1132-4.

2. Maduagwu SM, Maijindadi RD, Duniya KI, Oyeyemi AA, Saidu IA, Aremu BJ. Prevalence and patterns of work-related musculoskeletal disorders among bankers in Maiduguri, Northeast Nigeria. Occupational Medicine \& Health Affairs. 2014 Jun 30:1-6.

3. Kotwani SK, Sinha N, Panhale V. Prevalence of musculoskeletal discomfort in bank employees. International Journal of Innovative Research in Medical Science. 2019;4(1):44.

4. Al-Hourani Z, Nazzal M, Khader Y, Almhdawi K, Bibars AR. Work-related musculoskeletal disorders among Jordanian dental technicians: Prevalence and associated factors. Work. 2017 Jan 1;56(4):617-23.

5. Bethge M. Work-Related Medical Rehabilitation. Rehabilitation (Stuttg). 2017 Feb;56(1):14-21.

6. European Agency for Safety and Health at Work, “OSH in figures Work-Related Musculoskeletal Disorders in the EU Euroean Risk Observatory Report," European Agency for Safety and Health at Work, vol. 82, no. 6, p. 14, Bilbao, Spain, 2013.

7. Briggs AM, Woolf AD, Dreinhöfer K, Homb N, Hoy DG, Kopansky-Giles D, Åkesson K, March L. Reducing the global burden of musculoskeletal conditions. Bull World Health Organ. 2018;96(5):366-8.

8. Chang JH, Wu JD, Liu CY, et al. Prevalence of musculoskeletal disorders and ergonomic assessments of cleaners. Am J Ind Med. 2012;55(7):593-604. doi:10.1002/ajim.22064

9. Coyte PC, Asche CV, Croxford R, Chan B. The economic cost of musculoskeletal disorders in Canada. Arthritis Rheum. 1998; 11:315-25.

10. Sadeghian F, Raei M, Ntani G, Coggon D. Predictors of incident and persistent neck / shoulder pain in Iranian Workers: a cohort study. PLoS One. 2013;8(2):e57544. 
11. Larsson B, Søgaard K, Rosendal L. Work related neck - shoulder pain: a review on magnitude, risk factors, biochemical characteristics, clinical picture and preventive interventions. Best Pract Res Clin Rheumatol. 2007; 21(3):447-63.

12. Erick PN. Smith DR. a systematic review of musculoskeletal disorders among school teachers. BMC Musculoskelet Disord. 2011;12(260):13-7.

13. Melaku Hailu Temesgen, Gashaw Jember Belay, Asmare Yitayeh Gelaw, Balamurugan Janakiraman and Yaregal Animut. Burden of shoulder and/neck pain among school teachers in Ethiopia BMC Musculoskeletal Disorders (2019) 20:18 https://doi.org/10.1186/s12891-019-2397-3

14. Bongers PM, ljmker S, Van den Heuvel S, Blatter BM. Epidemiology of work related neck and upper limb problems: psychosocial and personal risk factors (part I) and effective interventions from a bio behavioural perspective (part II). Journal of occupational rehabilitation. 2006 Sep 1;16(3):272-95.

15. Kraatz S, Lang J, Kraus T, Mu E. The incremental effect of psychosocial workplace factors on the development of neck and shoulder disorders: a systematic review of longitudinal studies. Int Arch Occup Env Heal. 2013; 86:375-95.

16. Erick PN, Smith DR. Musculoskeletal disorders in the teaching profession: an emerging workplace hazard with significant repercussions for developing countries. Ind Health. 2015; 53:385-6.

17. Binder Al. Cervical spondylosis and neck pain. Bmj 2007;334(7592):527e31.

18. Hoy D, et al. The global burden of neck pain: estimates from the global burden of disease 2010 study. Ann Rheum Disease 2014;73(7):1309e15.

19. Vos T, et al. Global, regional, and national incidence, prevalence, and years lived with disability for 310 diseases and injuries, 1990e2015: a systematic analysis for the global burden of disease study 2015. The Lancet 2016;388(10053):1545e602.

20. Lucchini RG, London L. Global occupational health: current challenges and the need for urgent action. Annals Global Health. 2014;80(4):251-6.

21. Abraha TH, Demoz AT, Moges HG, Ahmmed AN. Predictors of back disorder among Almeda textile factory workers, North Ethiopia. BMC research notes. 2018 Dec 1;11(1):304. https://doi.org/10.1186/s13104-018-3440-4

22. Woolf AD, Brooks P, Åkesson K, Mody GM. Prevention of musculoskeletal conditions in the developing world. Best Pract Res Clin Rheumatol. 2008; 22(4):759-72.

23. Tamene A, Mulugeta H, Ashenafi T, Thygerson SM. Musculoskeletal Disorders and Associated Factors among Vehicle Repair Workers in Hawassa City, Southern Ethiopia. Journal of Environmental and Public Health. 2020 May 7;2020. https://doi.org/10.1155/2020/9472357

24. Kasaw Kibret A, Fisseha Gebremeskel B, Embaye Gezae K, Solomon Tsegay G. Work-Related Musculoskeletal Disorders and Associated Factors Among Bankers in Ethiopia, 2018. Pain Research and Management. 2020 Sep 8;2020., https://doi.org/10.1155/2020/8735169

25. Wami SD, Dessie A, Chercos DH. The impact of work-related risk factors on the development of neck and upper limb pain among low wage hotel housekeepers in Gondar town, Northwest Ethiopia: 
institution-based cross-sectional study. Environmental health and preventive medicine. 2019 Dec 1;24(1):27.

26. Henok A, Bekele T. Prevalence of musculoskeletal pain and factors associated with kyphosis among pedestrian back-loading women in selected towns of Bench Maji zone, Southwest Ethiopia. Ethiopian Journal of Health Development. 2017;31(2):103-9.

27. Mekonnen TH, Abere G, Olkeba SW. Risk factors associated with upper extremity musculoskeletal disorders among barbers in Gondar town, Northwest Ethiopia, 2018: a Cross-sectional study. Pain Research and Management. 2019 Apr 3;2019. https://doi.org/10.1155/2019/6984719

28. Lette A, Hussen A, Kumbi M, Nuriye S, Lamore Y. Musculoskeletal Pain and Associated Factors among Building Construction Workers in Southeastern Ethiopia. Ergonomics Int J 2019, 3(5): 000214.

29. Mekonnen TH, DG. Yenealem and Geberu DM. Physical environmental and occupational factors inducing work-related neck and shoulder pains among self-employed tailors of informal sectors in Ethiopia, 2019. Results from a community based cross-sectional study. BMC Public Health (2020) 20:1265. https://doi.org/10.1186/s12889-020-09351-8

30. Mekonnen TH, Kekeba GG, Azanaw J, Kabito GG. Prevalence and healthcare seeking practice of work-related musculoskeletal disorders among informal sectors of hairdressers in Ethiopia, 2019: findings from a cross-sectional study. BMC Public Health. 2020 Dec; 20:1-0. https://doi.org/10.1186/s12889-020-08888-y

31. Melese H, Gebreyesus T, Alamer A, Berhe A. Prevalence and associated factors of musculoskeletal disorders among cleaners working at Mekelle University, Ethiopia. Journal of Pain Research. 2020; 13:2239-2246.

32. Dagne D, Abebe SM, Getachew A. Work-related musculoskeletal disorders and associated factors among bank workers in Addis Ababa, Ethiopia: a cross-sectional study. Environmental health and preventive medicine. 2020 Dec;25(1):1-8. https://doi.org/10.1186/s12199-020-00866-5

33. Regassa TM, Lema TB, Garmomsa GN (2018) Work Related Musculoskeletal Disorders and Associated Factors among Nurses Working in Jimma Zone Public Hospitals, South West Ethiopia. Occup Med Health Aff 6: 279. DOI: 10.4172/2329-6879.1000279.

34. PRISMA-P Group, D. Moher, L. Shamseer et al., "Preferred reporting items for systematic review and meta-analysis protocols (PRISMA-P) 2015 statement," Systematic Reviews, vol. 4, no. 1, 2015.

35. The Joanna Briggs Institute. Critical appraisal tools for use in the JBI systematic reviews checklist for prevalence studies: The University of Adelaide. Available from: https://joannabriggs.org/sites/default/files/2019-05/JBI_Critical_Appraisal Checklist for_ Prevalence_Studies2017_0.pdf.

36. Higgins JP, Thompson SG. Quantifying heterogeneity in a meta-analysis. Stat Med. 2002;21(11):1539-58.

37. Stroup DF, Berlin JA, Morton SC, Olkin I, Williamson GD, Rennie D, et al. Meta-analysis of observational studies in epidemiology: a proposal for reporting. JAMA. 2000;283(15):2008-12. 
38. Azizpour Y, Delpisheh A, Montazeri Z, Sayehmiri K. Prevalence of low back pain in Iranian nurses: a systematic review and meta-analysis. BMC nursing. 2017 Dec 1;16(1):50. DOI 10.1186/s12912-0170243-1

39. CDC, work place health promotion, Work-Related Musculoskeletal Disorders \& Ergonomics. https://www.cdc.gov/workplacehealthpromotion/health-strategies/musculoskeletaldisorders/index.html. Last accessed on December, 16,2020.

\section{Figures}
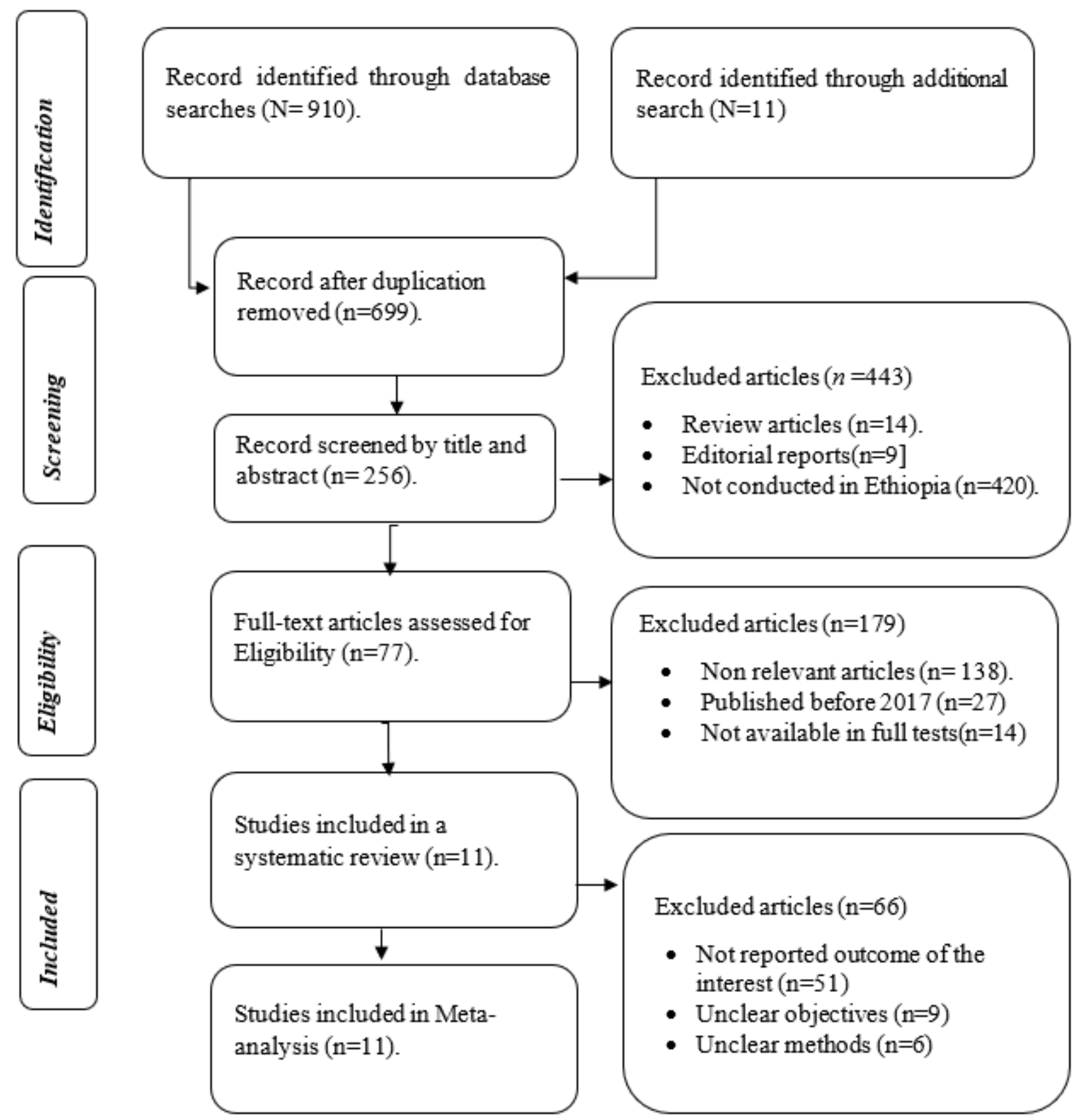

Figure 1 
Study selection process of included articles for a systematic review and Meta-analysis, 2020.

\section{Statistics for each study}

\section{Reference}

[23]

[24]

$[25]$

[26]

[27]

$[28]$

$[29]$

[30]

[31]

[32]

[33]

\section{Event Lower Upper \\ rate limit limit Z-Value p-Value}

$\begin{array}{lllll}0.610 & 0.557 & 0.660 & 4.047 & 0.000\end{array}$

$\begin{array}{lllll}0.296 & 0.248 & 0.349 & -6.930 & 0.000\end{array}$

$\begin{array}{lllll}0.540 & 0.492 & 0.587 & 1.642 & 0.101\end{array}$

$\begin{array}{lllll}0.682 & 0.636 & 0.725 & 7.299 & 0.000\end{array}$

$\begin{array}{lllll}0.271 & 0.230 & 0.316 & -8.982 & 0.000\end{array}$

$\begin{array}{llllll}0.105 & 0.079 & 0.139 & -13.301 & 0.000\end{array}$

$\begin{array}{lllll}0.721 & 0.676 & 0.762 & 8.716 & 0.000\end{array}$

$\begin{array}{lllll}0.537 & 0.499 & 0.575 & 1.888 & 0.039\end{array}$

$\begin{array}{lllll}0.140 & 0.103 & 0.187 & -10.234 & 0.000\end{array}$

$\begin{array}{lllll}0.409 & 0.374 & 0.444 & -4.973 & 0.000\end{array}$

$\begin{array}{lllll}0.141 & 0.106 & 0.185 & -10.911 & 0.000\end{array}$

$\begin{array}{lllll}0.379 & 0.265 & 0.508 & 1.835 & 0.047\end{array}$

Heterogeneity $($ I Squared $)=98.51 ; \mathrm{P}-$ Value $<0.0001$

Random effect model
Event rate and $95 \% \mathrm{CI}$

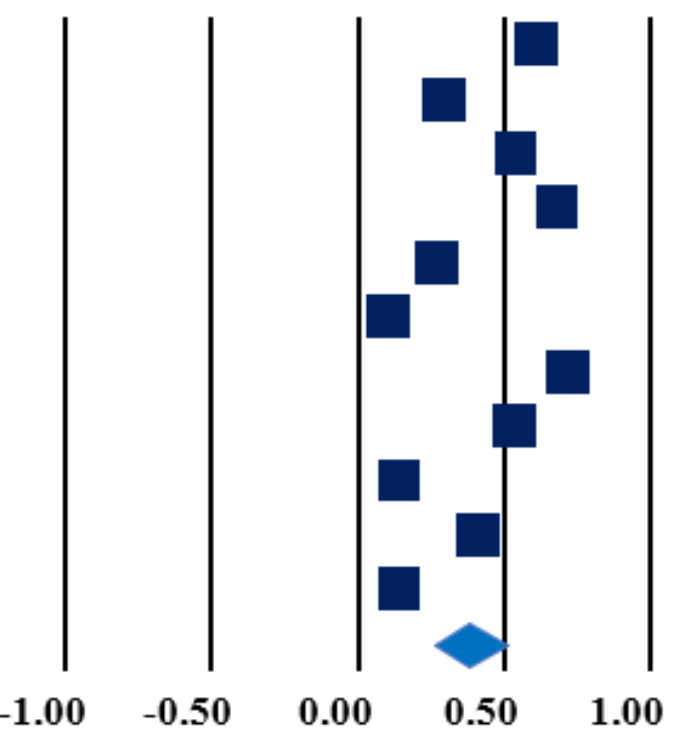

Figure 2

Forest plot shows the pooled prevalence of occupational-related shoulder pain in the previous one year in Ethiopia, 2020. 
Statistics for each study

\section{Reference}

[23]

[24]

[25]

[27]

[28]

[29]

[30]

[31]

[32]

[33]

Overall

Heterogeneity $($ I Squared) $=98.29 ;$ P-Value $<0.0001$

Random effect model

\section{Event Lower Upper}

rate limit limit $Z$-Value p-Value

$\begin{array}{lllll}0.152 & 0.118 & 0.194 & -11.447 & 0.000\end{array}$

$\begin{array}{lllll}0.352 & 0.301 & 0.407 & -5.107 & 0.000\end{array}$

$\begin{array}{lllll}0.507 & 0.459 & 0.554 & 0.288 & 0.774\end{array}$

$\begin{array}{lllll}0.293 & 0.251 & 0.339 & -8.187 & 0.000\end{array}$

$\begin{array}{llllll}0.076 & 0.054 & 0.106 & -13.404 & 0.000\end{array}$

$\begin{array}{lllll}0.683 & 0.637 & 0.726 & 7.311 & 0.000\end{array}$

$\begin{array}{lllll}0.534 & 0.496 & 0.572 & 1.735 & 0.083\end{array}$

$\begin{array}{llllll}0.095 & 0.065 & 0.137 & -10.739 & 0.000\end{array}$

$\begin{array}{lllll}0.380 & 0.346 & 0.415 & -6.529 & 0.000\end{array}$

$\begin{array}{lllll}0.240 & 0.195 & 0.291 & -8.541 & 0.000\end{array}$

$\begin{array}{lllll}0.299 & 0.201 & 0.419 & -3.167 & 0.002\end{array}$

$-1.00 \quad-0.50$

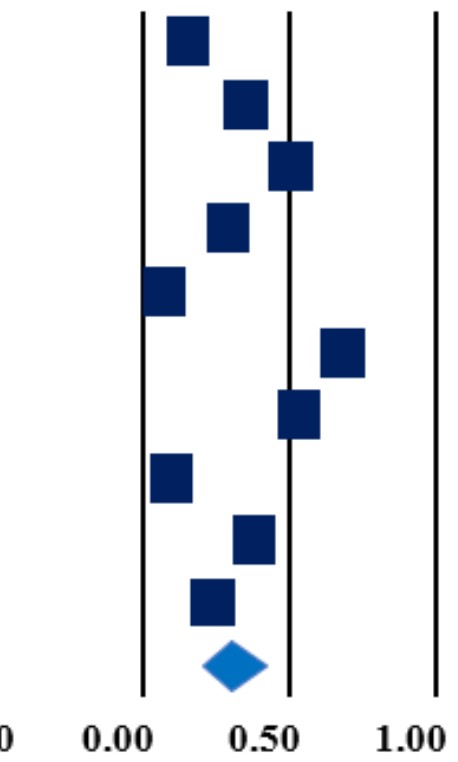

Figure 3

Forest plot shows the pooled prevalence of occupational-related neck pain in the previous one year in Ethiopia, 2020. 